\title{
Barrett's oesophagus: the new endoscopic modalities have a future
}

\section{J Deviere}

Gut 2005;54(Suppl I):i33-i37. doi: 10.1136/gut.2004.041574

Barrett's oesophagus is defined as the replacement of squamous oesophageal epithelium by intestinal metaplasia in the distal oesophagus. It is a fairly frequent complication of gastro-oesophageal reflux disease (GORD): $5-10 \%$ of patients with GORD suffer from Barrett's oesophagus. GORD is essential for the development of Barrett's oesophagus.' Intestinal metaplasia is a premalignant lesion that may further develop into dysplasia and lead to adenocarcinoma of the oesophagus. ${ }^{2}$ The latter now accounts for almost $50 \%$ of oesophageal cancer cases in western countries, and the largest increase in its incidence was recorded during the past two decades. ${ }^{3}$ Patients with Barrett's oesophagus have a 2-25\% risk of developing mild to severe dysplasia and a $2-5 \%$ risk of having adenocarcinoma: $30-150$ times higher than the risk in the general population. Forty to fifty per cent of Barrett's oesophagus patients with severe dysplasia would present adenocarcinoma within 5 years. ${ }^{45}$

\footnotetext{
Correspondence to: Professor J Deviere, Department of Gastroenterology and Hepatopancreatology, ULB - Hôpital Erasme, Route de Lennik 808, B - 1070 Brussels, Belgium; jdeviere@ulb.ac.be
}

M edical treatments using high doses of proton pump inhibitors (PPIs) or surgical treatments-for example, fundoplication-have been proposed to reverse Barrett's oesophagus and abrogate the trigger event in the cascade of the metaplasia, dysplasia, cancer sequence (namely GORD). On the one hand, retrospective surveys of surgical treatments have failed to demonstrate a significant benefit in Barrett's oesophagus regression and on the development of adenocarcinoma. ${ }^{6-8}$ However, high doses of PPIs offer only a modest remission with partial restoration of squamous islands within the intestinal metaplasia. ${ }^{9-15}$

The risk of surgery for patients with Barrett's oesophagus who develop oesophageal adenocarcinoma is very high with an operative mortality varying between 1.6 and $9.4 \% .{ }^{16}$ These patients are very often older, overweight with significant cardiac and respiratory problems. Moreover, the surgical resection for high grade dysplasia and early cancer still has an early morbidity of more than $50 \%$ and a late morbidity of $26 \%$ with an actuarial survival at 5 years of $79 \% .{ }^{17}$ Surgery is offering a "massive macroscopic morbid solution for a microscopic mucosal problem"18 in this setting; therefore, there is clearly a place for an alternative, less invasive treatment, which could offer curative treatment to nearly every patient.

Therapeutic endoscopic modalities have been directed towards:
- The destruction of non-dysplastic intestinal metaplasia in the hope of having a direct impact on the risk of tumour development (by replacement of the intestinal metaplasia by a squamous epithelium).

- The treatment of Barrett's oesophagus associated with low grade dysplasia (LGD).

- The treatment of severe dysplasia or intramucosal adenocarcinoma in patients who present this potential indication for surgical resection.

\section{DESTRUCTION OF NON-DYSPLASTIC BARRETT'S OESOPHAGUS}

With therapeutic endoscopy, ablation of Barrett's oesophagus is an attractive alternative treatment that could directly impact on the risk of tumour development. Recent studies using laser therapy (Nd-YAG), photodynamic treatment (PDT), and multipolar electrocoagulation (MPEC) could demonstrate, combined with profound acid suppression, significant Barrett's oesophagus regression with eradication of intestinal metaplasia and squamous re-epithelialisation of the targeted lesions. ${ }^{19-22}$ MPEC has been studied in this particular indication, showing that this treatment, associated with profound acid suppression (omeprazole, $80 \mathrm{mg} /$ day), was able to induce visual reversal of Barrett's oesophagus (assessed by lugol staining) in $85 \%$ of the cases and complete reversal (no gland demonstrated at biopsy) in $78 \%$ of the cases. However, no data of follow up longer than 6 months are currently available with this technique.

PDT is a more expensive technique. When used as a photosensitiser, porfimer sodium is associated with significant complications-oesophageal stricture occurring in a third of the PDT treated patients-and therefore its use in this particular indication is limited. PDT using 5-aminolevulinic acid (5-ALA) is associated with less complications but although effective ${ }^{23}$ has not been specifically studied for this indication.

\section{Argon plasma coagulation for removal of} non-dysplastic intestinal metaplasia

Argon plasma coagulation (APC) was the technique most extensively studied for the ablation of non-dysplastic Barrett's. This is a technique that is easy to use, effective, and allows treatment of large surface areas. The APC device consists of a contact-free monopolar high

Abbreviations: 5-ALA, 5-aminolevulinic acid; APC, argon plasma coagulation; GORD, gastro-oesophageal reflux disease; LET, local endoscopic treatment; LGD, low grade dysplasia; MPEC, multipolar electrocoagulation; PDT, photodynamic treatment; PPI, proton pump inhibitor 
frequency probe that delivers electrical energy through ionised plasma of argon gas to the target tissue, inducing tissue surface coagulation. The APC system (Argon beemer II, ERBE Elektromedizin, Tubingen, Germany) includes the argon gas source with gas flow meter, a high frequency electrosurgical generator, and flexible teflon delivery catheters, which can be passed through the therapeutic channel of the endoscope. Different diameters and lengths exist for the APC probes that can deliver the plasma parallel or perpendicular to the axis of the catheter. The coagulation depth is approximately controlled to $1-3 \mathrm{~mm}$ because of the physical properties of the electrically insulating zone of tissue desiccation, which confers increased electrical resistance and contributes to limit depth of coagulation. Depth of injury is dependent on generator power setting $(0-155 \mathrm{~W}$-that is, 30 to $90 \mathrm{~W}$ for Barrett's oesophagus ablation), argon gas flow rate $(0.5-7 \mathrm{~L} / \mathrm{mn}$ - that is, $1-2 \mathrm{~L}$ for Barrett's oesophagus ablation), probe tissue distance $(2-8 \mathrm{~mm})$, and duration of application (0.5-2 seconds or continuous). ${ }^{24}$ When applied in Barrett's oesophagus, APC generates a white coagulum either circumferentially, point by point for a short segment, or by achieving longitudinal strips in a backward direction during withdrawal of the endoscope.

\section{Short term results}

Short term results of studies evaluating the effectiveness of APC associated with PPI treatment for patients having nondysplastic oesophagus have shown that, after one to six APC sessions, a success rate of complete histological Barrett's oesophagus eradication ranging from $55-100 \%$ could be achieved. ${ }^{25}{ }^{26}$ Partial regression could also be observed in some patients with a significant Barrett's oesophagus length reduction. Higher success rates seemed to be observed by upgrading the APC power setting from 30-90 W but with increased incidence of strictures. ${ }^{27}{ }^{28}$ Yet, endoscopic ablation of Barrett's oesophagus (61-100\%) was not always associated with histological eradication of intestinal metaplasia (55$100 \%$ ). In fact, remaining buried glands and persisting intestinal metaplasia under the squamous re-epithelialisation were reported with a frequency of $0-44 \%$ in areas where Barrett's oesophagus was endoscopically eliminated. Again, the use of higher power setting of APC resulting in a deeper injury and higher PPI doses may account for the very low incidence of residual buried glands observed in some recent clinical trials.

\section{Complications}

Complications of this treatment include chest discomfort and odynophagia, which were very frequent. Although unusual, severe complications were not negligible and included strictures, ${ }^{27-29}$ fever, ${ }^{27}$ bleeding, ${ }^{29}$ or even perforation and death. ${ }^{27}{ }^{30-33}$ Perforations and strictures occurred early on during the trial at the beginning of the learning curve. Strictures were associated with higher APC power setting and required one to three balloon dilatations. Fever with pleural effusions was quite frequent in one study and may be related to micro-perforations. ${ }^{27}$ Perforations $(n=5)$ were the most serious complications: two of them resolved with conservative medical treatment and parenteral nutrition; three were referred for thoracotomy and drainage, two of which died postoperatively..$^{27} 30$ This is difficult to justify in patients with non-dysplastic Barrett's for whom endoscopic surveillance is effective. This is the reason why routine use of APC should be ruled out for this indication.

\section{Long term results}

Long term results were somewhat disappointing, with relapse of intestinal metaplasia with positive biopsies ranging from 0-68\% when performing endoscopic follow up in patients successfully treated. Recently, Kahaleh et al ${ }^{26}$ examined
39 patients on a median follow up of 36 months (12-46 months) in order to identify the predictive factors of Barrett's oesophagus remission. ${ }^{33}$ Multivariate analysis revealed that short Barrett's oesophagus and normalisation of acid exposure under PPI treatment (as demonstrated by 24 hour $\mathrm{pH}$ metry) were the only independent predictive factors for sustained long term re-epithelialisation. That length of Barrett's oesophagus is a predictive factor, already reported in previous studies, is obvious: short intestinal metaplasia areas are easier to eradicate than larger areas. Incomplete endoscopic eradication with the persistence of residual buried glands may indeed be predictive for early relapse of Barrett's oesophagus. Adequate and optimal acid suppression should have been guessed when recent clinical trials demonstrated almost no Barrett's oesophagus relapse with very high doses of PPI (omeprazole $60-120 \mathrm{mg}$ ). ${ }^{28}$ In the Kahaleh study, ${ }^{26}$ patients with normal $\mathrm{pH}$ monitoring relapsed less than patients with abnormal monitoring results (12.5\% v 83\%) while receiving PPIs. Similarly, Basu et a ${ }^{25}$ observed a higher rate of Barrett's oesophagus recurrence in patients who had reduced their PPI use. This suggests that, once the eradication is obtained, it should be followed by a life long treatment with high doses of PPIs to avoid recurrence (and that PPIs should be titrated, maybe on the basis of intragastric $\mathrm{pH}$ monitoring) to take into account nocturnal acid breakthrough. ${ }^{34-36}$ However, it is worth mentioning that patients taking PPIs with normal pH monitoring may still relapse. Indeed, both acid and biliary reflux are significantly higher in patients with Barrett's oesophagus than in controls or patients with GORD. ${ }^{37} 38$ Interestingly, a trend for more severe biliary reflux was observed among patients with persistent Barrett's oesophagus at the end of treatment in the Basu study. ${ }^{25}$ This emphasises that acid reflux is surely not the only factor to be considered when looking for the mechanisms affecting outcome of such treatment. ${ }^{39}$

Another concern with this technique is the description of two cases of adenocarcinoma arising under the squamous reepithelialisation. ${ }^{40}{ }^{41}$ These adenocarcinoma may have progressed during follow up from residual buried glands and may have been missed by routine surveillance biopsies. Such discovery is frightening when considering the high percentage of residual buried glands after treatment and the relapse rates of intestinal metaplasia on longer follow up. On a total follow up of 1735 patients/year, Morris et al ${ }^{33}$ did not observe the development of severe dysplasia or adenocarcinoma in their group of non-dysplastic Barrett's patients treated. This suggests a potential benefit of such treatment when compared with the statistical incidence of cancer in Barrett's oesophagus, which is approximately 120 patients/year follow up. In the long term follow up of all cases, ${ }^{26}$ we observed two cases of adenocarcinoma, which represent an incidence very similar to the one observed in the general Barrett's oesophagus population. This not only suggests that surveillance and biopsies targeting could not be avoided but even could become more difficult after treatment completion, because the lesion may be covered by squamous epithelium. This also questions the final objective of such ablative treatment - that is, cancer prevention.

\section{Cost effectiveness}

Cost effectiveness studies are not yet available for ablative treatments. If successful in all patients, the cost of a median of three endoscopic treatment sessions is not minor. Moreover, the cost of potential complication management must be taken into account and may be significant, especially when using higher power rate. Furthermore, life long maintenance treatment with high doses of PPI will also dramatically enhance the price of this ablative treatment. This would be justified if no further follow up were needed. 
However, considering that less than $50 \%$ of the patients are cleared from Barrett's oesophagus and, thus, that surveillance could not be avoided, APC in non-dysplastic Barrett's oesophagus increases the cost of Barrett's oesophagus patient's management without evidence of clinical benefit. Therefore, not only should it not be performed outside of rigorous clinical trials, but the potential usefulness of new trials should be carefully analysed.

\section{Conclusion}

Despite the availability of many clinical trials, there is currently no evidence that ablation treatment is indicated for non-dysplastic Barrett's oesophagus. This kind of treatment should clearly not be performed outside of carefully designed and approved clinical trials. Indeed, these patients have a low risk of cancer and surveillance is effective. The risks of ablation treatment are not negligible and there is no evidence that Barrett's oesophagus ablation will ultimately be of any benefit for these patients. Besides this pessimistic comment, it must be acknowledged that all studies on ablation treatment in this indication represent a phase of technology assessment and that they could become useful in the future if it was possible to identify, among the patients having intestinal metaplasia, those who are at the highest risk of developing dysplasia.

\section{ENDOSCOPIC ABLATION OF HIGH GRADE DYSPLASIA OR EARLY CANCER (MUCOSAL TYPE)}

This is the area where local endoscopic treatment (LET) is currently the most interesting because it competes with surgical resection with a lower morbidity and mortality. Mucosal type early cancers are known as having almost no risk of lymph node metastases. There are two main techniques that have been used successfully in this indication: PDT and mucosectomy.

\section{Photodynamic treatment}

PDT relies on the interaction of light, drug, and oxygen. This is a process in which a light-sensitive drug concentrates in neoplastic tissues. The drug is then activated by a laser light of an appropriate wavelength and results in the production of singlet oxygen, which then selectively damages the tissue. After drug administration, light can be delivered on a large surface area using specially designed balloons and, therefore, PDT has the potential to treat long segments of Barrett's oesophagus in which areas of dysplasia are endoscopically indistinguishable from non-dysplastic epithelium. PDT can be performed using a variety of different agents, the two major ones being porfimer sodium, a haematoporphyrin derivative, and 5-ALA. Using porfimer sodium and adjuvant YAG laser for removal of small remaining areas of Barrett's, Overholt et $a l^{42}$ have treated 100 patients: 73 patients having high grade dysplasia and 13 early cancer. They have used sodium porfimer as a photosensitiser (this is the only one available in the USA) and have observed, after a mean follow up of 19 months, an entire regression of LGD, high grade dysplasia, and tumours in $93 \%, 77 \%$, and $67 \%$ of the cases, respectively. However, less than half of the patients had complete regression of the Barrett's epithelium. The same group has also reported the preliminary results of a multicentre randomised study of the efficacy on PDT for the ablation of high grade dysplasia. ${ }^{43}$ They have demonstrated the occurrence of cancer in 13\% of the group treated by PDT versus $28 \%$ if the control group received only omeprazole after a mean follow up of 18.6 months; however, it must be noted that this treatment was complicated by the development of strictures in a third of the patients, most of which resolved after dilation procedures. Using these data in a mathematical model, PDT used for treatment of high grade dysplasia increases life expectancy and is cost effective when compared with endoscopic surveillance and surgical oesophagectomy. ${ }^{44}$

Another photosensitiser, 5-ALA, is a porphyrin precursor, which stimulates the endogenous production of protophorphyrin-IX, a potent photosensitiser, precursor of the heme, which accumulates in the mucosa rather than in the submucosa or the muscularis propria. The major advantages of this photosensitiser are that it can be administered orally, that there is little photosensitivity because of rapid metabolism, and that it is associated with less complication, such as strictures, because of the preferential accumulation into the mucosa. The first series ${ }^{45}$ reporting the use of PDT using 5ALA has reported a complete eradication (at a mean follow up of 10 months) of high grade dysplasia in 10 out of 10 cases and of early tumors in 17 of 22 cases, without severe complication or mortality. 5-ALA is still used by the same group, as well as other European groups, and seems easier, has less photosensitisation, is more acceptable for the patient, and has less complications. It is considered as part of the multimodal local endoscopic treatment ${ }^{46}$ and some groups have even advocated the possibility for using it in patients with LGD as it will be discussed later. ${ }^{47}$

\section{Endoscopic mucosal resection}

Endoscopic mucosal resection is a technique more and more often used for resection of superficial tumours or lesions in the gastrointestinal tract. ${ }^{18}$ Its application in Barrett's oesophagus has been reported by several groups. It offers the advantage of providing a pathological specimen, which may allow reclassification of the patients according to the pathological findings. Therefore, it may clearly select those patients who will need surgery as well as those in whom the resection was incomplete. Having performed mucosal resection in 25 patients with visible lesion within a Barrett's oesophagus, Nijhawan et $a l^{48}$ found superficial cancer in 13 patients, high grade dysplasia in four, and carcinoma or no dysplasia in eight. The potential problems associated with endoscopic mucosal resection is the technical training, which is needed to perform this type of intervention, and mainly the fact that resection should be targeted. Therefore, it is particularly suitable for visible lesions ${ }^{48}$ or for short segment Barrett's oesophagus. ${ }^{46}$ The results of endoscopic mucosal resection in 64 patients having visible high grade dysplasia or adenocarcinoma was reported by Ell et al. ${ }^{49}$ Interestingly, the authors reported that the patients were selected from a group of 130 referred patients of whom 34 were excluded for local endoscopic treatment, 29 were treated by PDT, and three were treated by APC. The 64 remaining patients were divided into two groups: a low risk group having lesions of less than $20 \mathrm{~mm}$, high grade dysplasia, or mucosal type adenocarcinoma, and 29 patients representing the high risk group with lesions of more than $20 \mathrm{~mm}$ and/or the presence of submucosal adenocarcinoma. They were able to obtain a complete local remission in $97 \%$ of the cases (34/35) for the first group with a mean follow up of 12 months. Interestingly, they also noted during the follow up the development of metachronous lesion in $17 \%$ of the cases. For the high risk group, they had no major complication but of the 29 patients initially selected only 22 were effectively treated with a curative intent, the others having been referred for surgery. Among them, a complete local remission after a mean follow up of 10 months was observed in $59 \%$ of the cases. Only one severe complication was reported, which was bleeding not controlled at the initial endoscopy. The same group reported also on the treatment of high grade dysplasia or mucosal cancer in 50 patients with short segment Barrett's. ${ }^{46}$ These represented $43 \%$ of all the patients with Barrett's oesophagus referred for treatment of high grade dysplasia or mucosal 
cancer. In this group, mucosectomy was clearly the major technique of LET-offered alone in $28 / 50$ cases and in combination in four additional cases. This group in $2003^{50}$ reported an average follow up of 50 months (with a minimum of 3 years) in a group of 114 patients with high grade dysplasia $(n=19)$ or mucosal cancer $(n=95)$. The treatment applied included EMR, PDT, or both. Five patients were reclassified after EMR and referred for surgery. Complete local remission was achieved in $97 \%$ of the patients. Thirty five per cent developed metachronous lesions retreated endoscopically. On the whole follow up, only one patient died from oesophageal cancer (and 13 from other causes). The mean age of their patients was 65 years and the calculated 5 years survival of the treated population was $79 \%$, which was not significantly different from that of the same age German population. With these data, this group recommends for the first time that endoscopic approach should replace radical oesophagectomy in this indication as treatment of choice.

Taken together, these data suggest that ablation treatment is clearly feasible in the setting of high grade dysplasia or mucosal cancer complicating Barrett's oesophagus. Mucosectomy and PDT (using 5-ALA) are minimally invasive and could replace surgery in certain conditions. The availability of these techniques also has an impact on surveillance because every patient, even older and in poor clinical condition, could be offered a potential curative treatment. For patients fit for major surgery, this is the potential minimally invasive treatment of high grade dysplasia, which is the most attractive because of the fact that only a minority of these patients will develop cancer over the next 5 years. This will even become more interesting if molecular markers predicting the risk of tumour development in this subgroup become available.

There is no doubt the LET in this setting will have a future and is already starting to become established as a treatment of choice since long term data have become available from expert centres. However, it clearly appears that the development of metachronous lesions represents a major concern and requires close surveillance after LET. The programme of surveillance should also be clearly defined ${ }^{45}$ and explained to the patients because additional LET can be successfully proposed.

\section{BARRETT'S OESOPHAGUS ASSOCIATED WITH LGD}

This represents the group of patients for whom there is no consensus about the need for treatment. Although almost all the ablative treatments have been shown able to eradicate LGD, the potential impact on the development of tumour is not known. This is however the only group where a randomised study is available ${ }^{47}$ (and could be performed). Using 5-ALA PDT plus omeprazole versus omeprazole alone the authors were able to achieve regression of LGD in 100\% in the ALA group versus $33 \%$ in the placebo group at 1 year. Longer follow up of these patients has been recently published $^{23}$ at a median of 53 months with sustained regression in all but one patient. One patient developed a tumour in an untreated area of Barrett's oesophagus after 3 years. Because of the low rate of complications of PDT when using 5-ALA as a photosensitiser, these data suggest that it could be offered to patients having LGD despite adequate PPI treatment. The place of mucosal resection for short segment Barrett's oesophagus with LGD would also deserve further evaluation before entering the clinical routine.

In conclusion, local endoscopic treatments are currently purely experimental for non-dysplastic Barrett's oesophagus and much more promising for the treatment of high grade dysplasia or mucosal tumour, especially in high risk patients where they could become considered as a first choice treatment. The availability of these techniques allows a proposal of a curative treatment to everyone diagnosed with an early lesion in the setting of a surveillance programme. More long term data are awaited and specific surveillance programmes after LET will have to be evaluated, because of the high incidence of metachronous lesions.

\section{REFERENCES}

1 Katzka DA, Rustgi AK. Gastrooesophageal reflux disease and Barrett's oesophagus. Med Clin North Am 2000;84:1137.

2 Hameeteman W, Tytgat GN, Houthoff HJ, et al. Barrett's oesophagus: development of dysplasia and adenocarcinoma. Gastroenterology 1989:96:1249.

3 Lagergren J, Bergstrom R, Lindgren A, et al. Symptomatic gastrooesophageal reflux as a risk factor for oesophageal adenocarcinoma. N Engl J Med 1999;340:825.

4 Spechler SJ. Barrett's oesophagus: diagnosis and management. Baillires Best Pract Res Clin Gastroenterol 2000; 14:857.

5 Spechler SJ. Clinical practice. Barrett's oesophagus. N Engl J Med 2002;346:836.

6 Attwood SE, Barlow AP, Norris TL, et al. Barrett's oesophagus: effect of antireflux surgery on symptom control and development of complications. Br J Surg 1992;79:1050.

7 Williamson WA, Ellis FH, Gibb SP, et al. Effect of antireflux operation on Barrett's mucosa. Ann Thorac Surg 1990;49:537.

8 Sagar PM, Ackroyd R, Hosie KB, et al. Regression and progression of Barrett's oesophagus after antireflux surgery. Br J Surg 1995;82:806.

9 Bozymski EM, Shaheen NJ. Barrett's oesophagus: acid suppression, but no regression. Am J Gastroenterol 1997;92:556.

10 Cooper BT, Neumann CS, Cox MA, et al. Continuous treatment with omeprazole $20 \mathrm{mg}$ daily for up to 6 years in Barrett's oesophagus. Aliment Pharmacol Ther 1998;12:893.

11 Devière J, Buset M, Dumonceau JM, et al. Regression of Barrett's epithelium with omeprazole. N Engl J Med 1989;320:1497.

12 Gore S, Healey CJ, Sutton R, et al. Regression of columnar lined (Barrett's) oesophagus with continuous omeprazole therapy. Aliment Pharmacol Ther 1993;7:623

13 Malesci A, Savarino V, Zentilin P, et al. Partial regression of Barrett's oesophagus by long-term therapy with high-dose omeprazole. Gastrointest Endosc 1996;44:700

14 Neumann CS, lqbal TH, Cooper BT. Long term continuous omeprazole treatment of patients with Barrett's oesophagus. Aliment Pharmacol Ther 1995;9:451

15 Wilkinson SP, Biddlestone L, Gore S, et al. Regression of columnar-lined (Barrett's) oesophagus with omeprazole $40 \mathrm{mg}$ daily: results of 5 years of continuous therapy. Aliment Pharmacol Ther 1999;13:1205.

16 Bollschweiler $\mathbf{E}$, Schorder W, Holscher AH, et al. Postoperative risk analysis in patient with adenocarcinoma or squamous cell carcinoma of the oesophagus. Br J Surg 2000;87:1106.

17 Zaninotto, Parenti AR, Ruol A, et al. Oesophageal resection for high-grade dysplasia in Barrett's oesophagus. Br J Surg 2000;97:1002.

18 Barr H. Ablative mucosectomy is the procedure of choice to prevent Barrett's cancer. Gut 2003;52:14

19 Barham CP, Jones RL, Biddlestone LR, et al. Photothermal laser ablation of Barrett's oesophagus: endoscopic and histological evidence of squamous reepithelialisation. Gut 1997;41:281

20 Overholt BF, Panjehpour M, Haydek JM. Photodynamic therapy for Barrett's oesophagus: follow-up in 1000 patients. Gastrointest Endosc 1999:49:1.

21 Sampliner RE, Faigel D, Fennerty MB, et al. Effective and safe endoscopic reversal of nondysplastic Barrett's oesophagus with thermal electrocoagulation combined with high-dose acid inhibition: a multicenter study. Gastrointest Endosc 2001;53:554.

22 Sharma $\mathbf{P}$, Jaffe $P E$, Bhattacharyya $A$, et al. Laser and multipolar electrocoagulation ablation of early Barrett's adenocarcinoma: long-term follow-up. Gastrointest Endosc 1999;49:442.

23 Ackroyd R, Kelty CJ, Brown NJ, et al. Eradication of dysplastic Barrett's oesophagus using photodynamic therapy: long-term follow-up. Endoscopy 2003;35:496-501.

24 Ginsberg GG, Barkun AN, Bosco JJ, et al. The argon plasma coagulator: February 2002. Gastrointest Endosc 2002;55:807.

25 Basu KK, Pick B, Bale R, et al. Efficacy and one year follow up of argon plasma coagulation therapy for ablation of Barrett's oesophagus: factors determining persistence and recurrence of Barrett's epithelium. Gut 2002:51:776.

26 Kahaleh M, Van Laethem JL, Nagy N, et al. Long term follow-up and factors predictive of recurrence in Barrett's oesophagus treated by argon plasma therapy and acid suppression. Endoscopy 2002;12:950.

27 Pereira-Lima JC, Busnello JV, Saul C, et al. High power setting argon plasma coagulation for the eradication of Barrett's oesophagus. Am J Gastroenterol 2000;95:1661.

28 Schulz H, Miehlke S, Antos D, et al. Ablation of Barrett's epithelium by endoscopic argon plasma coagulation in combination with high-dose omeprazole. Gastrointest Endosc 2000;51:659.

29 Van Laethem JL, Cremer M, Peny MO, et al. Eradication of Barrett's mucosa with argon plasma coagulation and acid suppression: immediate and mid term results. Gut 1998;43:747. 
30 Byrne JP, Armstrong GR, Attwood SE. Restoration of the normal squamous lining in Barrett's oesophagus by argon beam plasma coagulation. Am J Gastroenterol 1998;93:1810

31 Grade AJ, Shah IA, Medlin SM, et al. The efficacy and safety of argon plasma coagulation therapy in Barrett's oesophagus. Gastrointest Endosc 1999:50:18.

32 Mork H, Barth T, Kreipe HH, et al. Reconstitution of squamous epithelium in Barrett's oesophagus with endoscopic argon plasma coagulation: a prospective study. Scand J Gastroenterol 1998;33:1130.

33 Morris CD, Byrne JP, Armstrong GR, et al. Prevention of the neoplastic progression of Barrett's oesophagus by endoscopic argon beam plasma ablation. Br J Surg 2001;88:1357.

34 Katz PO, Anderson C, Khoury R, et al. Gastro-oesophageal reflux associated with nocturnal gastric acid breakthrough on proton pump inhibitors. Aliment Pharmacol Ther 1998;12:1231-4.

35 Peghini PL, Katz PO, Bracy NA, et al. Nocturnal recovery of gastric acid secretion with twice-daily dosing of proton pump inhibitors. Am J Gastroenterol 1998;93:763-7.

36 Yeh RW, Gerson LB, Triadafilopoulos G. Efficacy of esomeprazole in controlling reflux symptoms, intraoesophageal, and intragastric $\mathrm{pH}$ in patients with Barrett's oesophagus. Dis Oesophagus 2003;16:193-8.

37 Martinez de Haro L, Ortiz A, Parrilla P, et al. Intestinal metaplasia in patients with columnar lined oesophagus is associated with high levels of duodenogastrooesophageal reflux. Ann Surg 2001;233:34.

38 Menges M, Muller M, Zeitz M. Increased acid and bile reflux in Barrett's oesophagus compared to reflux esophagitis, and effect of proton pump inhibitor therapy. Am J Gastroenterol 2001;96:331.

39 Ouatu-Lascar R, Fitzgerald RC, Triadafilopoulos G. Differentiation and proliferation in Barrett's oesophagus and the effects of acid suppression. Gastroenterology 1999;117:327.

40 Shand A, Dallal H, Palmer K, et al. Adenocarcinoma arising in columnar lined oesophagus following treatment with argon plasma coagulation. Gut $2001 ; 48: 580$
41 Van Laethem JL, Peny MO, Salmon I, et al. Intramucosal adenocarcinoma arising under squamous re-epithelialisation of Barrett's oesophagus. Gut 200, 46:574.

42 Overholt BF, Panjehpour M, Haydek JM. Photodynamic therapy for Barrett's oesophagus: follow-up in 100 patients. Gastrointest Endosc 1999;49:1.

43 Overholt BF, Haggitt RC, Bonner MP, et al. A multicenter, partially blinded, randomized study of the efficacy of photodynamic therapy (PDT) using porfimer sodium (POR) for the ablation of high-grade dysplasia (HGD) in Barrett's oesophagus (BE): results of 24-month follow-up (abstract). Gastroenterology 2003;124:A151.

44 Hur C, Nishioka NS, Gazelle GS. Cost-effectiveness of photodynamic therapy for treatment of Barrett's oesophagus with high grade dysplasia. Dig Dis Sci 2003:48: 1273-83.

45 Gossner $L$, Stolte $M$, Sroka $R$, et al. Photodynamic ablation of high grade dysplasia and early cancer in Barrett's oesophagus by means of 5 aminolevulinic acid. Gastroenterology 1998;114:448.

46 May A, Gossner L, Pech O, et al. Intraepithelial high grade neoplasia and early adenocarcinoma in short-segment Barrett's oesophagus (SSBE): curative treatment using local endoscopic techniques. Endoscopy 2002;34:604.

47 Ackroyd R, Brown NJ, Davis MF, et al. Photodynamic therapy for dysplastic Barrett's oesophagus: a prospective, double blind, randomised, placebo controlled trial. Gut 2000;47:612.

48 Niihawan PK, Wang KK. Endoscopic mucosal resection for lesions with endoscopic features suggestive of malignancy and high grade dysplasia within Barrett's oesophagus. Gastrointest Endosc 2000;52:328-32.

49 Ell C, May A, Gossner L, et al. Endoscopic mucosal resection of early cancer and high grade dysplasia in Barrett's oesophagus. Gastroenterology 2000;1 18:670.

50 Pech O, May A, Gossner L, et al. Long-term results of local endoscopic therapy for intraepithelial high-grade neoplasia and early adenocarcinoma in Barrett's oesophagus. Digestive Disease Week, 2003;abstract 691. 